\title{
Apolipoprotein E-Deficient Lipoproteins Induce Foam Cell Formation by Activation of PERK-EIF-2a Signaling Cascade
}

\author{
YanFeng Zhao ${ }^{1,2}$, ZhongMao Guo ${ }^{1,2}$, XingHua Lin ${ }^{1}$, LiChun Zhou ${ }^{1}$, Emmanuel U. Okoro ${ }^{1}$, GuoHuang Fan ${ }^{3}$, Raju Ramaswamy and \\ Hong Yang ${ }^{1 *}$ \\ ${ }^{1}$ Department of Physiology, Meharry Medical College, Nashville, TN 37208 \\ ${ }^{2}$ Wuhan University School of Basic Medical Science, Wuhan, P.R. China, 430071 \\ ${ }^{3}$ Department of Pharmacology and Toxicology, Virginia Commonwealth University School of Medicine, Richmond, VA 23298 \\ ${ }^{4}$ Department of Microbiology and Immunology, Meharry Medical College, Nashville, TN 37208
}

\begin{abstract}
Transformation of macrophages into foam cells by apolipoprotein (Apo) E-deficient, ApoB48-containing (E-/B48) lipoproteins has been shown to be associated with increased phosphorylation of eukaryotic initiation factor-2 $\alpha$ (elF$2 \alpha$ ). The present report examined the causal relationship between elF-2 $\alpha$ phosphorylation and lipid accumulation in macrophages induced by E-/B48 lipoproteins. E-/B48 lipoproteins increased elF-2a phosphorylation and cholesterol ester accumulation, while lipoprotein degradation decreased and lysosomal acid lipase and cathepsin B mRNA translation was inhibited in mouse peritoneal macrophages (MPMs). These responses were overcome by overexpression of a nonphosphorylatable elF-2 $\alpha$ mutant in MPMs. Incubation of MPMs with E-/B48 lipoproteins also increased the phosphorylation of RNA-dependent protein kinase-like endoplasmic reticulum kinase (PERK), but not other elF-2a kinases. Overexpression of a nonphosphorylatable PERK mutant inhibited PERK and elF-2 $\alpha$ phosphorylation, and alleviated cholesterol ester accumulation induced by E-/B48 lipoproteins. PERK is an elF-2 $\alpha$ kinase activated by endoplasmic reticulum (ER) stress. Taken together, findings from this report suggest that induction of ER stress, i.e., activation of the PERK-eIF2 $\alpha$ signaling cascade, is a mechanism by which E-/B48 lipoproteins down-regulate lysosomal hydrolase synthesis, inhibit lysosomal lipoprotein degradation, and increase intracellular lipoprotein and cholesterol ester accumulation, resulting in foam cell formation.
\end{abstract}

Keywords: Endoplasmic reticulum stress; Foam cells; Apolipoprotein E-deficient lipoproteins; Eukaryotic initiation factor- $2 \alpha$; eIF-2 $\alpha$ kinase

\section{Introduction}

Transformation of macrophages into foam cells is a hallmark of early atherosclerosis (Glass and Witztum, 2001; Tiwari et al., 2008). We previously reported that incubation of mouse peritoneal macrophages (MPMs) with apolipoprotein (Apo) E-deficient, ApoB48containing (E-/B48) lipoproteins resulted in intralysosomal lipoprotein accumulation and foam cell formation. These responses were also associated with a reduced degradation rate of $\mathrm{E}-/ \mathrm{B} 48$ lipoproteins and reduced lysosomal acid lipase (LAL) and cathepsin B (Cath B) protein level (Wu et al., 2007). LAL is the sole hydrolase responsible for cleavage of cholesteryl esters delivered to lysosomes, and Cath $\mathrm{B}$ is one of the lysosomal proteases responsible for degradation of endocytic proteins, including the protein components of lipoproteins (O'Neil et al.,2003; Zschenker et al., 2006).Thus, reduction in lysosomal hydrolases could be a fundamental mechanism by which E-/B48 lipoproteins trigger intracellular lipid accumulation.

A more recent report from our laboratory demonstrated that transformation of macrophages into foam cells by E-/B48 lipoproteins was associated with increased phosphorylation of eukaryotic initiation factor- $2 \alpha$ (eIF-2 $\alpha$ ) (Wu et al., 2008). Under physiological conditions, phosphorylation of eIF- $2 \alpha$ induces cellular events to alleviate endoplasmic reticulum (ER) stress, such as inhibition of global protein synthesis and upregulation of protein chaperones (Schröder and Kaufman 2005; Zhao and Ackerman 2006) However, constant phosphorylation of eIF-2 $\alpha$ might overpower normal cellular functions, causing pathological conditions. (Schröder and Kaufman 2005; Zhao and Ackerman 2006) For example, in macrophages treated with $\mathrm{E}$-/B48 lipoproteins, reduction in lysosomal hydrolase synthesis might induce intracellular lipid/lipoprotein accumulation, leading to foam cell formation. The present report determined the causal role of eIF-2 $\alpha$ phosphorylation in E-/B48 lipoprotein-induced foam cell formation. Our data demonstrated that inhibition of eIF$2 \alpha$ phosphorylation by overexpression of a nonphosphorylatable eIF-2 $\alpha$ mutant in MPMs alleviated the suppressive effect of E-/B48 lipoproteins on lysosomal hydrolase synthesis, and inhibited cellular lipid accumulation.

In mammalian cells, four elF- $2 \alpha$ kinases have been identified, which mediate elF- $2 \alpha$ phosphorylation in response to various stressful cellular events (Lewerenz and Maher 2009; Wek et al., 2006). Endoplasmic reticulum (ER) stress activates RNA-dependent protein kinase-like endoplasmic reticulum kinase (PERK). Heme deprivation activates heme-regulated inhibitor (HRI). Virus infection activates double-stranded RNA-activated protein kinase (PKR). Amino acid deprivation activates general control non-derepressible-2 (GCN2) (Wek et al., 2006). Data from this report demonstrated that incubation of MPMs with $\mathrm{E}^{-} / \mathrm{B} 48$ lipoproteins induced phosphorylation of PERK, but not other eIF- $2 \alpha$ kinases, such as PKR and GCN2. Overexpression of a nonphosphorylatable PERK mutant attenuated eIF- $2 \alpha$ phosphorylation and reduced cholesterol ester accumulation in macrophages induced by E-/B48 lipoproteins. These observations indicate that induction of ER stress, i.e., activation of

*Corresponding author: Hong Yang, M.D. or ZhongMao Guo, M.D., Ph.D. Department of Physiology, Meharry Medical College, Nashville, TN 37208, Tel: (615) 327-5772; Fax: (615) 321-2949; E-mail: ZGUO@mmc.edu, HYANG@mmc. edu

Received September 10, 2010; Accepted October 06, 2010; Published October 07, 2010

Citation: Zhao Y, Guo Z, Lin X, Zhou L, Okoro EU, et al. (2010) Apolipoprotein E-Deficient Lipoproteins Induce Foam Cell Formation by Activation of PERKEIF-2a Signaling Cascade. J Bioanal Biomed 2: 113-120. doi:10.4172/1948 593X.1000033

Copyright: ( $) 2010$ Zhao $Y$, et al. This is an open-access article distributed under the terms of the Creative Commons Attribution License, which permits unrestricted use, distribution, and reproduction in any medium, provided the original author and source are credited. 
the PERK-eIF2 $\alpha$ signaling cascade, is a causal mechanism by which $\mathrm{E}-/$ B48 lipoproteins transform macrophages into foam cells.

\section{Materials and Methods}

\section{Materials}

Tissue culture reagents, unless otherwise indicated, were obtained from Invitrogen (Carlsbad, CA). Antibodies against PERK, eIF-2 $\alpha$, phosphorylated eIF-2 $\alpha$ (eIF2 $\alpha-p)$, ATF4, PKR, phosphorylated PKR (PKR-p), Cath $B$, and $\beta$-tubulin were obtained from Santa Cruz Biotechnology, Inc. (Santa Cruz, CA). Antibodies against LAL and phosphorylated PERK (PERK-p) were obtained from Cell Signaling Technology (Danvers, MA). Antibodies against GCN2 and phosphorylated GCN2 (GCN2-p) were obtained from Abcam Inc. (Cambridge, MA). Mouse LAL full-length cDNA was obtained from Open Biosystems (Huntsville, AL). M-PER mammalian protein extraction reagent and BCA protein assay kit were purchased from Pierce (Rockford, IL).

\section{Animals}

Low-density lipoprotein receptor-deficient $\left(L D L R^{\prime-}\right)$ mice, mice expressing ApoB48 and not B100 $\left(A p o B^{48 / 48}\right)$, and ApoE-deficient mice expressing ApoB48 and not B100 (ApoB $\left.B^{48 / 48} / A p o E^{\prime}\right)$ were obtained from Jackson Laboratory (Bar Harbor, ME). The $L D L R$-deficient mice expressing ApoB48 and not $\mathrm{B} 100\left(A p o B^{48 / 48} / L D L R^{-}\right)$were produced in our laboratory by crossbreeding $L D L R^{-}$mice with $A p o B^{48 / 48}$ mice. The $A p o B^{48 / 48} / A p o E^{-/}$and $A p o B^{48 / 48} / L D L R^{-}$mice at 3-4 months of age were fed a high-fat diet containing $15 \%$ fat and $1.25 \%$ cholesterol by weight (Harlan Teklad, Madison, WI) for 4 days. Blood $(0.5-1 \mathrm{ml})$ was collected from the posterior vena cava after mice were anesthetized with $0.03 \mathrm{ml}$ of cocktail containing $80 \mathrm{mg} / \mathrm{ml}$ ketamine hydrochloride and $12 \mathrm{mg} / \mathrm{ml}$ xylazine hydrochloride. To minimize oxidation, collected blood was immediately mixed with $50 \mu \mathrm{M}$ butylated hydroxytoluene and $2 \mathrm{mM}$ EDTA and cooled on ice. All procedures for handling animals were conducted following protocols approved by the Institutional Animal Care and Use Committee at Meharry Medical College.

\section{Lipoprotein isolation}

The ApoE- and ApoB48-carrying ( $\left.\mathrm{E}^{+} / \mathrm{B} 48\right)$ lipoproteins and the ApoE-deficient, ApoB48-carrying (E-/B48) lipoproteins were isolated from $A p o B^{48 / 48} / L D L R^{-/}$and $A p o B^{48 / 48} / A p o E^{-}$mice plasma, respectively. Briefly, mouse plasma was overlaid with a potassium bromide $(\mathrm{KBr})$ gradient solution ( $d: 1.006$ ) and centrifuged at $650,000 \mathrm{~g}$ for $2 \mathrm{hrs}$ in a Sorvall M150 ultracentrifuge (Kendro Laboratory Products, Asheville, $\mathrm{NC}$ ). The upper fraction containing very low-density lipoproteins was discarded. The density of the bottom fraction was adjusted to 1.063 with a $\mathrm{KBr}$ gradient solution. The resulting mixture was centrifuged at $650,000 \mathrm{~g}$ for $2.5 \mathrm{hrs}$. The lipoproteins were collected, dialyzed in phosphate buffered saline (PBS, pH 7.4) containing $10 \mathrm{mM}$ EDTA for 48 hrs at $4^{\circ} \mathrm{C}$, and filtered through a $0.45-\mu \mathrm{m}$ filter ${ }^{3}$. Protein concentrations were determined by BCA protein assays using bovine serum albumin (BSA) as a standard.

\section{Construction of expression vectors for $\mathrm{LAL}$ and nonphosphorylatable mutants of eIF-2 $\alpha$ and PERK}

The LAL overexpression vector was generated by inserting a full-length LAL cDNA into a pEGFP-N1 plasmid (Clontech, Mountain View, CA). The plasmid vector for expression of an elF- $2 \alpha$ mutant was constructed as previously described (Donzé et al., 1995). Serine 51 of the mouse eIF- $2 \alpha$ was substituted by alanine (eIF2 $\alpha$ -
S51A), so that it could not serve as a substrate for elF- $2 \alpha$ kinases, but still competed with endogenous elF- $2 \alpha$ for binding eIF- $2 \alpha$ kinases. Briefly, eIF- $2 \alpha$ cDNA was amplified using the following PCR primers: 1) forward 5'- gacCTCGAGatgccggggctaagttgtaga-3' and reverse $5^{\prime}$-gacAAGCTTatcttcagctttggcttc-3'. The amplified fragment was inserted into a pEGFP-N1 plasmid. To generate eIF2 $\alpha$-S51A, site-directed mutagenesis was performed to substitute serine 51 of elF- $2 \alpha$ with alanine using the GeneEditor site-directed mutagenesis system (Promega, Madison, WI) and the oligo-nucleotide 5 ' -gaattagccagacgacg-3'.

The plasmid vector for expression of the PERK mutant was constructed by subcloning a PERK-K618A mutant into a pEGFP-N1 expression plasmid. The PERK-K618A mutant, in which lysine 618 was replaced with an alanine, was kindly provided by Dr. David Ron (Skirball Institute, New York University School of Medicine). The PERK-K618A mutant cannot autophosphorylate or phosphorylate eIF$2 \alpha$ (Harding et al., 1999).

\section{Cell culture and DNA transfection}

A MPM cell line (Raw 264.7) was obtained from ATCC (Rockville, $\mathrm{MD}$ ) and was transfected with the pEGFP vector containing the eIF2 $\alpha$ S51A mutant or an empty pEGFP vector using a Gene Pulser Xcell Electroporation System (Bio-Rad, Hercules, CA). The transfected cells were cultured in Dulbecco's modified Eagle's medium (DMEM) supplemented with $10 \%$ fetal bovine serum (FBS) and $1 \mathrm{mg} / \mathrm{ml} \mathrm{G} 418$ for 3 weeks. The transfected cells were then sorted by flow cytometry (FACStar PLUS flow cytometer, Becton Dickinson, Sydney, Australia). The stably transfected cells were maintained in DMEM containing $10 \% \mathrm{FBS}$ and $500 \mu \mathrm{g} / \mathrm{ml} \mathrm{G} 418$.

Transient transfection of Raw 264.7 cells was performed using a Nucleofector II (Lonza, Walkersville, MD) according to the manufacturer's instructions. Briefly, $2 \times 10^{6}$ cells were mixed with $3 \mu \mathrm{g}$ of LAL or PERK-K618A overexpression vectors or pEGFP empty vector, and pulsed with the appropriate Nucleofector program. The cells were then transferred into pre-warmed medium and cultured for another $24 \mathrm{hrs}$ before lipoprotein treatment.

\section{Binding, association, and degradation of ${ }^{125}$-labeled lipoproteins}

The $\mathrm{E}^{+} / \mathrm{B} 48$ or $\mathrm{E}^{-} / \mathrm{B} 48$ lipoproteins were labeled with ${ }^{125} \mathrm{I}$ as previously described (Wu et al., 2005). For the binding study, Raw 264.7 cells grown in 6-well plates to confluency were pre-chilled on ice for $30 \mathrm{~min}$ and incubated with various concentrations of ${ }^{125}$-labeled lipoproteins on ice for 4 additional hrs. Cells were washed twice with ice-cold PBS and lysed with $0.5 \mathrm{ml}$ of $0.5 \mathrm{M} \mathrm{NaOH}$. The radioactivity in the lysates was counted using a universal $\gamma$-counter (1282 Compugamma; Perkin-Elmer Life and Analytic Science, Shelton, CT).

For the association and degradation experiments, Raw 264.7 cells were incubated with $20 \mu \mathrm{g} / \mathrm{ml}{ }^{125}$-labeled $\mathrm{E}^{+} / \mathrm{B} 48$ or El̂/B48 lipoproteins at $37^{\circ} \mathrm{C}$. After various incubation times, $0.75 \mathrm{ml}$ of culture medium was removed from each well and mixed with $0.25 \mathrm{ml}$ ice-cold $40 \%$ trichloroacetic acid (TCA) and $0.2 \mathrm{ml}$ of $0.7 \mathrm{M} \mathrm{AgNO}_{3}$ to precipitate the free iodine. After centrifugation at $700 \mathrm{x} g$ for $10 \mathrm{~min}$, the radioactivity levels of the supernatants were determined. The amount of ${ }^{125}$ I-labeled lipoprotein particles degraded by macrophages was estimated by the non-TCA-precipitated radioactivity in the culture medium and was normalized by incubation time. Cells were washed twice with PBS and lysed in $0.5 \mathrm{M} \mathrm{NaOH}$. A $10-\mu$ l lysate aliquot was 
used for protein measurement, and the remaining lysate was used to determine cell-associated radioactivity. The amount of lipoproteins that was taken up by cells was the sum of the lipoproteins that were associated with the cells and the lipoproteins that were degraded by the cells within the incubation time period. Thus, we calculated the lipoprotein uptake using the following equation: uptake $=$ association + degradation.

\section{Cholesterol analysis}

Raw 264.7 cells grown in 6-well plates to confluency were incubated with $20 \mu \mathrm{g} / \mathrm{ml} \mathrm{E}^{+} / \mathrm{B} 48$ or E-/B48 lipoproteins or culture medium alone for 48 hrs followed by a 12-hr equilibration in lipoprotein-free medium. After removal of the culture medium, cells were washed 3 times with ice-cold PBS and scraped into $1 \mathrm{ml}$ distilled water. Lipids were extracted with chloroform:methanol $(2: 1 \mathrm{v} / \mathrm{v})$. The organic phase was collected and dried under a vacuum. Dried pellets were dissolved in $50 \mu \mathrm{l}$ isopropanol containing $10 \%$ Triton $\mathrm{X}-100$. Cellular total cholesterol (TC) and free cholesterol (FC) levels were determined using enzymatic kits (WAKO Chemicals, Richmond, VA). The level of esterified cholesterol (EC) was calculated using the following formula: $\mathrm{EC}=\mathrm{TC}-\mathrm{FC}^{3}$.

\section{Western blot analysis}

Raw 264.7 cells grown in 6-well plates to confluency were treated with $20 \mu \mathrm{g} / \mathrm{ml} \mathrm{E}^{+} / \mathrm{B} 48$ or E-/B48 lipoproteins or culture medium alone for 12 hrs. Cells were washed twice with ice-cold PBS and lysed with M-PER reagent with freshly added protease inhibitor and a phosphatase cocktail [ $1 \mathrm{mM} \mathrm{Na}_{3} \mathrm{VO}_{4}, 1 \mathrm{mM}$ dithiothreitol (DTT), and $1 \mathrm{mM}$ phenylmethylsulfonyl fluoride (PMSF)]. Protein concentrations in the lysates were determined using a BCA protein assay kit. Equal amounts of proteins were subjected to $10 \%$ sodium dodecyl sulfatepolyacrylamide gel electrophoresis (SDS-PAGE). The proteins were then transferred to polyvinylidene fluoride (PVDF) membranes. Membranes were blocked with 5\% fat-free milk in TBS-T ( $2.5 \mathrm{mM}$ Tris, $15 \mathrm{mM} \mathrm{NaCl}$, and $0.01 \%$ Tween $20 ; \mathrm{pH} \mathrm{7.6)}$ at room temperature for $1 \mathrm{hr}$, and consequently incubated with specific primary antibodies and horseradish peroxidase-conjugated secondary antibody. After incubation with ECL plus detection reagent (GE healthcare, Piscataway, NJ), the chemiluminescence signals were captured by an $\mathrm{x}$-ray film. The intensity of the protein bands was analyzed with a Bio-Rad Model GS-700 Imaging Densitometer (Bio-Rad).

Fractionation of polysomes and isolation of total and polysome-associated RNA

Raw 264.7 cells grown in 100-mm culture dishes to confluency were treated with $20 \mu \mathrm{g} / \mathrm{ml} \mathrm{E}$ - $/ \mathrm{B} 48$ lipoproteins or culture medium alone for 4 hrs. After two washes with ice-cold PBS, cells were harvested by scraping into a hypotonic solution containing $10 \mathrm{mM}$ Tris-Cl, $5 \mathrm{mM} \mathrm{MgCl}$, and $0.5 \%$ Ivory detergent (Daskal et al., 1976). Lysates were centrifuged at $13,000 \mathrm{~g}$ for $10 \mathrm{~min}$ at $4^{\circ} \mathrm{C}$ to remove cell debris and nuclei. For polysomal fractionation, the cytoplasm extract was layered on a $10 \mathrm{ml}$ continuous sucrose gradient $(5-40 \%$ sucrose in $15 \mathrm{mM} \mathrm{MgCl}, 15 \mathrm{mM}$ Tris-Cl, and $0.3 \mathrm{M} \mathrm{NaCl}$ ). After a 6-hr centrifugation at $280,000 \mathrm{~g}$ at $4^{\circ} \mathrm{C}$ in a SW41 Ti rotor (Beckman Coulter, Inc., Brea, CA), the absorbance at $254 \mathrm{~nm}$ was measured continuously as a function of the gradient depth in an UV monitor (UPC900, Amersham Biosciences, Piscataway, NJ). The positions of non-polysomal ribosomes and polysomes in the polysome profile were identified by calibration with $70 \mathrm{~S} E$. coli ribosomes centrifuged in parallel gradients. The area under the curve representing polysomes was integrated and normalized to the total area under the curve. The percentage derived from this calculation is defined as the global translation efficiency, which is a reflection of de novo protein synthesis (Koritzinsky et al., 2006).

Total RNA was extracted from cell lysates using RNeasy Plus Mini Kits (Qiagen, Valencia, CA) as per the manufacturer's instructions. For isolation of polysome-associated RNAs, cytoplasmic extracts were layered over $1.35-\mathrm{M}$ sucrose solutions and centrifuged at $310,000 \mathrm{~g}$ for $80 \mathrm{~min}$ at $4^{\circ} \mathrm{C}$ with a $70 \mathrm{Ti}$ Beckman fixed angle rotor (Wu et al., 2008). Pellets containing polysomes were collected and polysomeassociated RNA was extracted using a Qiagen RNeasy Plus Mini Kit.

\section{Quantitative real-time reverse transcription-polymerase chain reaction (RT-PCR) analysis}

Quantitative RT-PCR was performed with total RNA and polysomeassociated RNA using an iQ5 system (Bio-Rad). After DNase treatment, $3 \mu \mathrm{g}$ of RNA was reverse-transcribed using PolyT and Superscript III First-Strand reverse transcriptase (Invitrogen). The resulting cDNA products were amplified in triplicate using a QuantiFast ${ }^{\mathrm{TM}}$ SYBR Green PCR Kit (Qiagen) in a total reaction volume of $20 \mu \mathrm{l}$. Reactions were performed with $300 \mathrm{nM}$ of each primer and 1-10 ng cDNA depending on the abundance of the gene of interest. Primers for the indicated genes were designed in our laboratory or in commercial laboratories according to information in GenBank. A standard curve for glyceraldehyde-3-phosphate dehydrogenase (GAPDH) mRNA was generated by 10 -fold serial dilutions of macrophage cDNA. Relative quantities of the target genes were estimated for each sample by amplifying the target genes simultaneously with the GAPDH standard curve. GAPDH is a suitable gene for normalization because it has shown little variation following treatment with E-/B48 lipoproteins (Wu et al., 2008).

\section{Statistical analysis}

Data were reported as mean \pm standard error of the mean (SEM). Data distribution was examined by the Shapiro-Wilk normality test. Comparisons among groups treated with $\mathrm{E}^{+} / \mathrm{B} 48$ or $\mathrm{E}^{-} / \mathrm{B} 48$ lipoproteins or culture medium alone were performed using oneway or two-way analysis of variance followed by Student's t tests. Differences were considered significant at a $P$ values less than 0.05 $(P<0.05)$. All statistical analyses were performed using Stastix software (Analytical Software, Tallahassee, FL). The number of replicate experiments performed is indicated in the figure legends.

\section{Results}

\section{Overexpression of the eIF2 $\alpha$-S51A mutant inhibited endogenous elF-2 $\alpha$ phosphorylation induced by E-/B48 lipoproteins}

Recently, we demonstrated that transformation of macrophages into foam cells by E-/B48 lipoproteins was associated with enhanced phosphorylation of elF- $2 \alpha$ (Wu et al., 2008). The present study examined the effect of a nonphosphorylatable elF-2 $\alpha$ mutant on E-/B48 lipoprotein-induced eIF- $2 \alpha$ phosphorylation. $\mathrm{E}^{+} / \mathrm{B} 48$ lipoproteins did not significantly affect the phosphorylation and protein levels of eIF$2 \alpha$ in macrophages transfected with either an empty pEGFP plasmid vector or the eIF2 $\alpha$-S51A mutant (Figure 1). In contrast, E-/B48 lipoproteins elevated both the phosphorylated and the total protein levels of eIF- $2 \alpha$ in the empty vector-transfected cells. Elevation of phosphorylated eIF-2 $\alpha$ occurred to a larger extent, in the E-/B48 lipoprotein-treated cells than in the untreated control macrophages $(81.97 \pm 16.99$ versus $25.11 \pm 1.02, P<0.05)$, significantly elevating the ratio of phosphorylated versus total elF- $2 \alpha$. In addition, E-/B48 

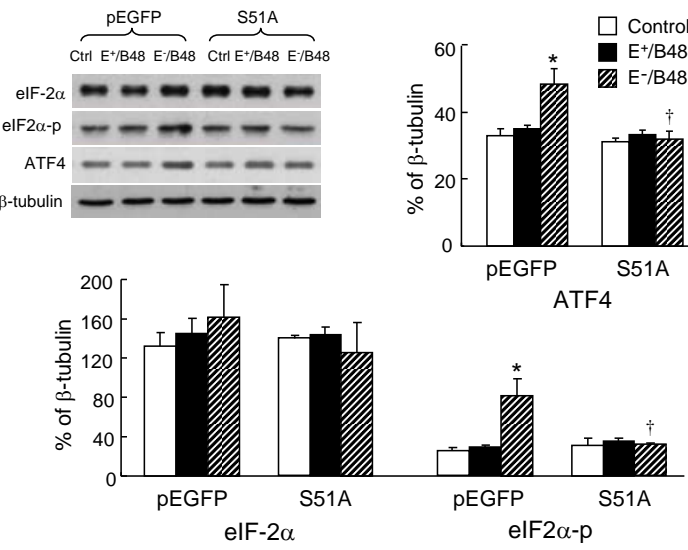

Figure 1: Transfection of macrophages with the elF2 $\alpha-S 51 \mathrm{~A}$ mutant attenuated E-/B48 lipoprotein-induced activation of the elF2 $\alpha-$ ATF4 signaling pathway. Raw 264.7 cells were stably transfected with a plasmid vector expressing elF $2 \alpha-$ S51A (S51A) or an empty pEGFP vector. The cells were incubated at $37^{\circ} \mathrm{C}$ for $24 \mathrm{hrs}$ with $20 \mu \mathrm{g} / \mathrm{ml}$ of $\mathrm{E}^{+} / \mathrm{B} 48$ or $\mathrm{E}-/ \mathrm{B} 48$ lipoproteins or culture medium alone (control). The levels of total elF-2 $\alpha$ and ATF4 proteins and the levels of phosphorylated elF-2 $\alpha$ (elF2 $\alpha-p)$ were determined by western blot analysis and expressed relative to $\beta$-tubulin levels. Values represent the mean \pm SEM of five separate experiments. ${ }^{*} P<0.05$ as compared with the control, and ${ }^{\dagger} P<0.05$ as compared with cells transfected with empty pEGFP vector and treated with $\mathrm{E}-/$ B48 lipoproteins.

\begin{tabular}{|c|c|c|c|c|c|c|}
\hline & \multicolumn{3}{|c|}{ pEGFP-transfected cells } & \multicolumn{3}{|c|}{ S51A-transfected cells } \\
\hline & Control & $\mathrm{E}^{+} / \mathrm{B} 48$ & E-/B48 & Control & $\mathrm{E}^{+} / \mathrm{B} 48$ & E-/B48 \\
\hline \multicolumn{7}{|c|}{ Total RNA } \\
\hline LAL & $0.15 \pm 0.02$ & $0.21 \pm 0.03^{*}$ & $0.18 \pm 0.03$ & $0.18 \pm 0.02$ & $0.20 \pm 0.03$ & $0.22 \pm 0.03$ \\
\hline Cath B & $0.53 \pm 0.04$ & $0.69 \pm 0.09^{*}$ & $0.57 \pm 0.07$ & $0.66 \pm 0.09$ & $0.67 \pm 0.09$ & $0.72 \pm 0.08$ \\
\hline ATF4 & $0.20 \pm 0.02$ & $0.21 \pm 0.03$ & $0.23 \pm 0.05$ & $0.18 \pm 0.03$ & $0.17 \pm 0.03$ & $0.19 \pm 0.03$ \\
\hline \multicolumn{7}{|c|}{ Polysome-associated RNA } \\
\hline LAL & $0.29 \pm 0.02$ & $0.26 \pm 0.02$ & $0.21 \pm 0.03^{*}$ & $0.29 \pm 0.06$ & $0.31 \pm 0.04$ & $0.32 \pm 0.04^{\dagger}$ \\
\hline Cath B & $0.24 \pm 0.02$ & $0.25 \pm 0.04$ & $0.17 \pm 0.02^{*}$ & $0.27 \pm 0.02$ & $0.26 \pm 0.01$ & $0.28 \pm 0.01^{\dagger}$ \\
\hline ATF4 & $0.63 \pm 0.12$ & $0.64 \pm 0.05$ & $0.91 \pm 0.11^{*}$ & $0.69 \pm 0.11$ & $0.61 \pm 0.09$ & $0.73 \pm 0.10^{\dagger}$ \\
\hline \multicolumn{7}{|c|}{$\begin{array}{l}\text { LAL; lysosomal acid lipase, Cath B; cathepsin B, ATF4; activating transcription factor } 4 \\
\text { aSteady-state level of each mRNA was expressed relative to GAPDH mRNA levels. } \\
\text { bPolysome-associated mRNA levels were normalized with respect to its steady-state } \\
\text { level. } \\
\text { Values represent the mean } \pm \text { SEM of five experiments. } \\
{ }^{*} P<0.05 \text { as compared with the control, and } \dagger P<0.05 \text { as compared with the cells } \\
\text { transfected with empty pEGFP vector and treated with EÎ/B48 lipoproteins. }\end{array}$} \\
\hline
\end{tabular}

Table 1: Differential regulation of steady-state levels and translational efficiencies of specific mRNAs in Raw 264.7 cells treated with E-/B48 lipoproteins.

lipoprotein treatment increased ATF4 protein levels (Figure 1). and enhanced the translational efficiency of ATF4 mRNA (Table 1) in empty vector-transfected cells. In contrast, incubation of the eIF2 $\alpha$ S51A-transfected cells with E-/B48 lipoproteins did not alter the eIF$2 \alpha$ phosphorylation level or the ATF4 mRNA translation efficiency. These observations imply that overexpression of the eIF2 $\alpha$-S51A mutant inhibits E-/B48 lipoprotein-induced eIF-2 $\alpha$ phosphorylation and subsequent cellular events, including increased ATF4 mRNA translation.

Overexpression of the eIF2 $\alpha$-S51A mutant attenuated the reduction of global mRNA translation caused by E-/B48 lipoproteins

One consequence of elF- $2 \alpha$ phosphorylation is the reduction in global mRNA translation (Wek et al., 2006). In this study, we examined the effect of E-/B48 lipoproteins and the eIF2 $\alpha-S 51 \mathrm{~A}$ mutant on overall mRNA translation efficiency by measuring the level of polysome-associated mRNA. Figure 2A-D show representative polysome profiles, in which polysomes containing actively translated mRNAs and two or more ribosomes are separated from monomer ribosomes, ribosomal subunits, and non-translated mRNAs. Incubation of the empty vector-transfected macrophages with $\mathrm{E}$-/B48 lipoproteins (Figure 2B) caused a large reduction in high molecular weight polysomes and a corresponding increase in free ribosomes and ribosomal subunits when compared to untreated cells (Figure 2A). In contrast, E-/B48 lipoproteins did not alter the polysome profile in cells overexpressing the eIF2 $\alpha$-S51A mutant (Figure 2D vs. 2C). To quantitatively assess global mRNA translation, we calculated the percentage of RNA associated with polysomes, which is a reflection of overall mRNA translation efficiency (Koritzinsky et al., 2006; van den Beucken et al., 2006). As shown in Figure 2E, the calculated value for global mRNA translation fell from $41 \%$ to $29 \%$ after the empty vector-transfected cells were treated with E-/B48 lipoproteins, which is consistent with E-/B48 lipoprotein-reduced incorporation of ${ }^{35} \mathrm{~S}$-labelled methionine and cysteine into newly synthesized proteins (Wu et al., 2008). On the other hand, E-/B48 lipoproteins did not reduce global mRNA translation efficiency in the eIF2 $\alpha$-S51A-transfected cells. These data suggest that enhancing elF-2 $\alpha$ phosphorylation is a mechanism by which $\mathrm{E}^{-} / \mathrm{B} 48$ lipoproteins inhibit overall mRNA translation in macrophages.

\section{Overexpression of the elF2 $\alpha$-S51A mutant increased E-/B48 lipoprotein catabolism}

We demonstrated the inhibitory effect of the eIF2 $\alpha-S 51 \mathrm{~A}$ mutant on phosphorylation of endogenous elF- $2 \alpha$ caused by $\mathrm{E}^{-} / \mathrm{B} 48$ lipoproteins. Therefore, we then examined the effect of this eIF- $2 \alpha$ mutant on $\mathrm{E}^{-} / \mathrm{B} 48$ lipoprotein catabolism in macrophages. The amount of $\mathrm{E}^{+} / \mathrm{B} 48$ and $\mathrm{E}^{-} / \mathrm{B} 48$ lipoproteins bound to the cell surface increased with the concentration of lipoproteins in the culture medium (Figure $3 \mathrm{~A}$ and $3 \mathrm{D}$ ). The amount of $\mathrm{E}^{+} / \mathrm{B} 48$ and $\mathrm{E} / \mathrm{B} 48$ lipoproteins taken up
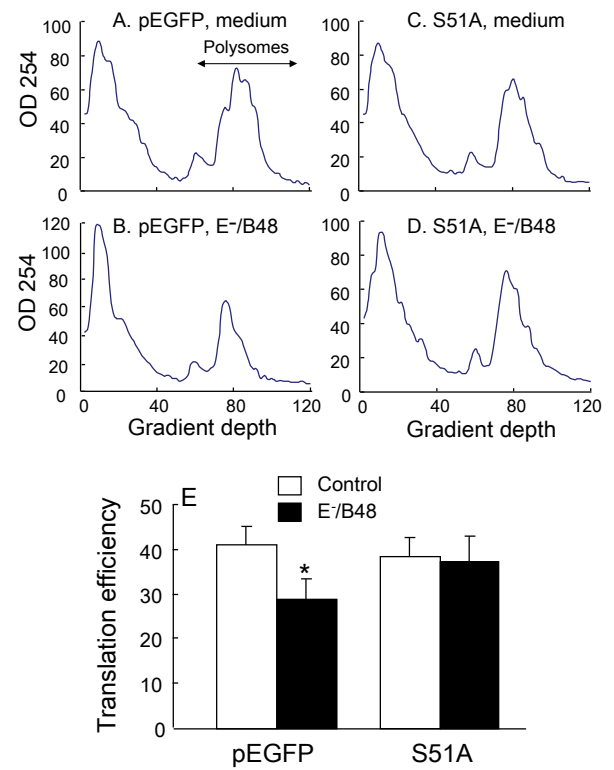

Figure 2: Transfection of macrophages with the elF2 $\alpha-S 51 \mathrm{~A}$ mutant attenuated the E-/B48 lipoprotein-induced inhibitory effect on global mRNA translational efficiency. Raw 264.7 cells were stably transfected with a plasmid vector expressing elF2 $\alpha-S 51 \mathrm{~A}(\mathrm{~S} 51 \mathrm{~A})$ or an empty pEGFP vector. The pEGFP- (A and $B$ ) and S51A-transfected ( $C$ and D) cells were incubated with $20 \mu \mathrm{g} / \mathrm{ml}$ of $E^{-} / B 48$ lipoproteins ( $B$ and $D$ ) or culture medium alone ( $A$ and $C$ ). Polysomal and nonpolysomal RNAs were separated on sucrose gradients. The optical densities at $254 \mathrm{~nm}$ were plotted as a function of gradient depth. Translation efficiency was expressed as the percentage of the integrated area under the polysome fraction of the curve relative to the total area under both the polysome and non-polysome fractions $(E)$ 

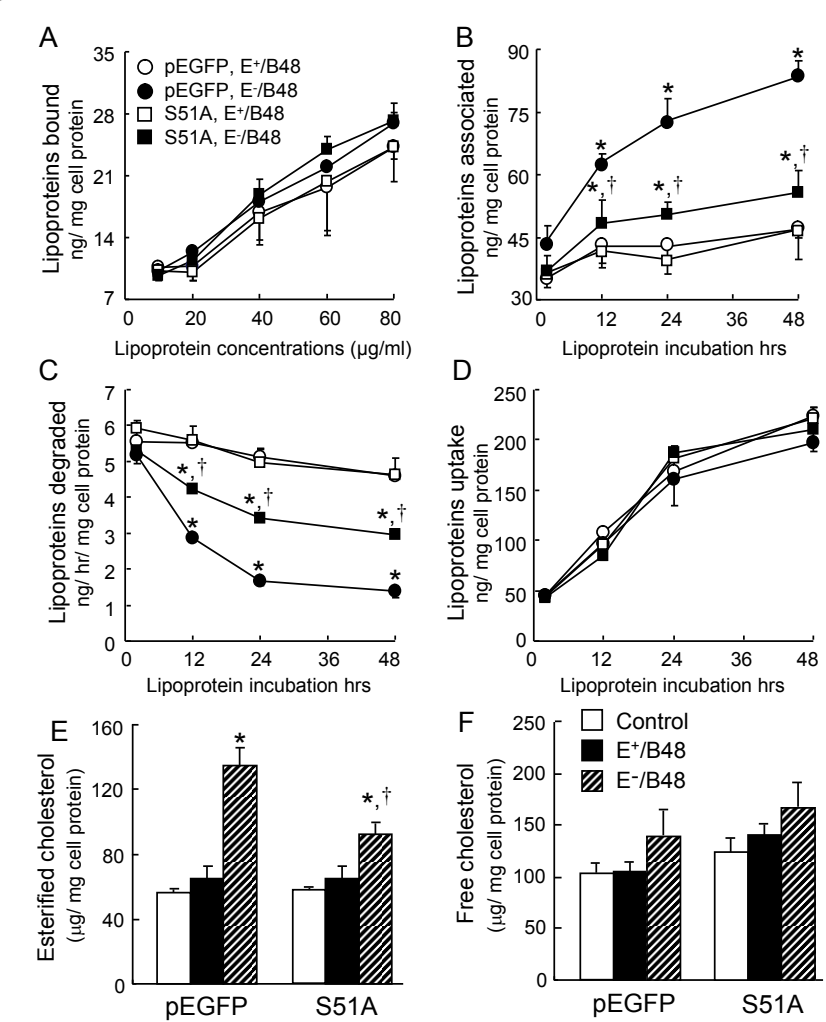

Figure 3: The effect of the elF2 $\alpha-S 51 A$ mutant on E-/B48 lipoprotein catabolism. Raw 264.7 cells were stably transfected with a plasmid vector expressing elF2a-S51A (S51A) or an empty pEGFP vector. (A) The transfected cells were incubated with various concentrations of 125 l-labeled $E+/ B 48$ or E-/B48 lipoproteins on ice for $4 \mathrm{hrs}$. The level of radioactivity bound to the cells was determined. (B, C, and D) Cells were incubated with $20 \mu \mathrm{g} / \mathrm{ml}$ of ${ }^{125}$-labeled $\mathrm{E}+/ \mathrm{B} 48$ or $\mathrm{E}-/ \mathrm{B} 48$ lipoproteins at $37^{\circ} \mathrm{C}$. Culture medium was collected at the indicated incubation times to determine the amount of degraded 125I-labeled lipoprotein particles. Cells were lysed to estimate the amount of cell-associated $125 \mathrm{I}$-labeled lipoproteins. The uptake of lipoproteins was calculated as the sum of the associated and degraded lipoproteins at the given incubation time point. ( $E$ and $F$ ) Raw 264.7 cells were incubated at $37^{\circ} \mathrm{C}$ for $48 \mathrm{hrs}$ with $20 \mu \mathrm{g} / \mathrm{ml}$ of $\mathrm{E}+1$ B48 or E-/B48 lipoproteins or culture medium alone. Cellular cholesterol contents were determined. Values represent the mean \pm SEM of five experiments. ${ }^{*} \mathrm{P}<0.05$ as compared with the control, and $\mathrm{H} P<0.05$ as compared with cells transfected with empty $p E G F P$ vector and treated with E-/B48 lipoproteins.

by macrophages increased over time. Additionally, the macrophages transfected with the empty vector or the eIF2 $\alpha$-S51A mutant showed comparable capabilities to bind and take-up $\mathrm{E}^{+} / \mathrm{B} 48$ and E-/B48 lipoproteins (Figure 3A and 3D).

However, the amount of lipoproteins associated with, or degraded by, macrophages varied with the different treatments. Incubation of macrophages with the lipoproteins at $37^{\circ} \mathrm{C}$ induced a time-related increase in cell-associated lipoproteins (Figure 3B). The amount of $\mathrm{E}^{+} /$ B48 lipoproteins associated with the cells peaked within $12 \mathrm{hrs}$, and remained unchanged thereafter. There was no significant difference between cells transfected with the empty vector or the eIF $2 \alpha-S 51 \mathrm{~A}$ mutant. In contrast, the cell-associated levels of E-/B48 lipoproteins increased continuously over time. The magnitude of the increase was significantly lower in cells transfected with the eIF2 $\alpha$-S51A mutant than in cells transfected with the empty vector. Correspondingly, the amount of E-/B48 lipoproteins degraded by macrophages decreased over time (Figure $3 \mathrm{C}$ ). The magnitude of decline was also significantly less in cells transfected with the eIF2 $\alpha$-S51A mutant than in those transfected with the empty vector. Data in figure $3 \mathrm{C}$ also show that the degradation rate of $\mathrm{E}^{+} / \mathrm{B} 48$ lipoproteins remained unchanged over time in the cells transfected with the empty vector or the eIF $2 \alpha-S 51 \mathrm{~A}$ mutant. These data suggest that overexpression of the eIF2 $\alpha-\mathrm{S} 51 \mathrm{~A}$ mutant is able to preserve the capability of macrophages to degrade E-/B48 lipoproteins and to reduce intracellular E-/B48 lipoprotein accumulation.

Accumulation of esterified cholesterol is a hallmark of foam cells (Tiwari et al., 2008). Therefore, we measured free and esterified cholesterol levels in macrophages. Data in Figure 3E and 3F show that incubation of macrophages with $\mathrm{E}^{+} / \mathrm{B} 48$ lipoproteins did not significantly alter the cholesterol content in cells transfected with the empty vector or the eIF2 $\alpha$-S51A mutant, as compared to cells without lipoprotein treatment. However, incubation of the empty vector-transfected cells with E-/B48 lipoproteins for 48 hrs increased the esterified cholesterol level by $120 \%$. E-/B48 lipoprotein treatment also increased the esterified cholesterol level in cells transfected with the eIF2 $\alpha$-S51A mutant, but the increased magnitude was about $50 \%$ lower than that of the empty vector-transfected cells. E-/B48 lipoproteins did not significantly alter the free-cholesterol content in the cells transfected with the empty vector or the eIF2 $\alpha$-S51A mutant (Figure 3F). These data suggest that eIF- $2 \alpha$ phosphorylation plays an important role in the formation of foam cells induced by $\mathrm{E}^{-} / \mathrm{B} 48$ lipoproteins.

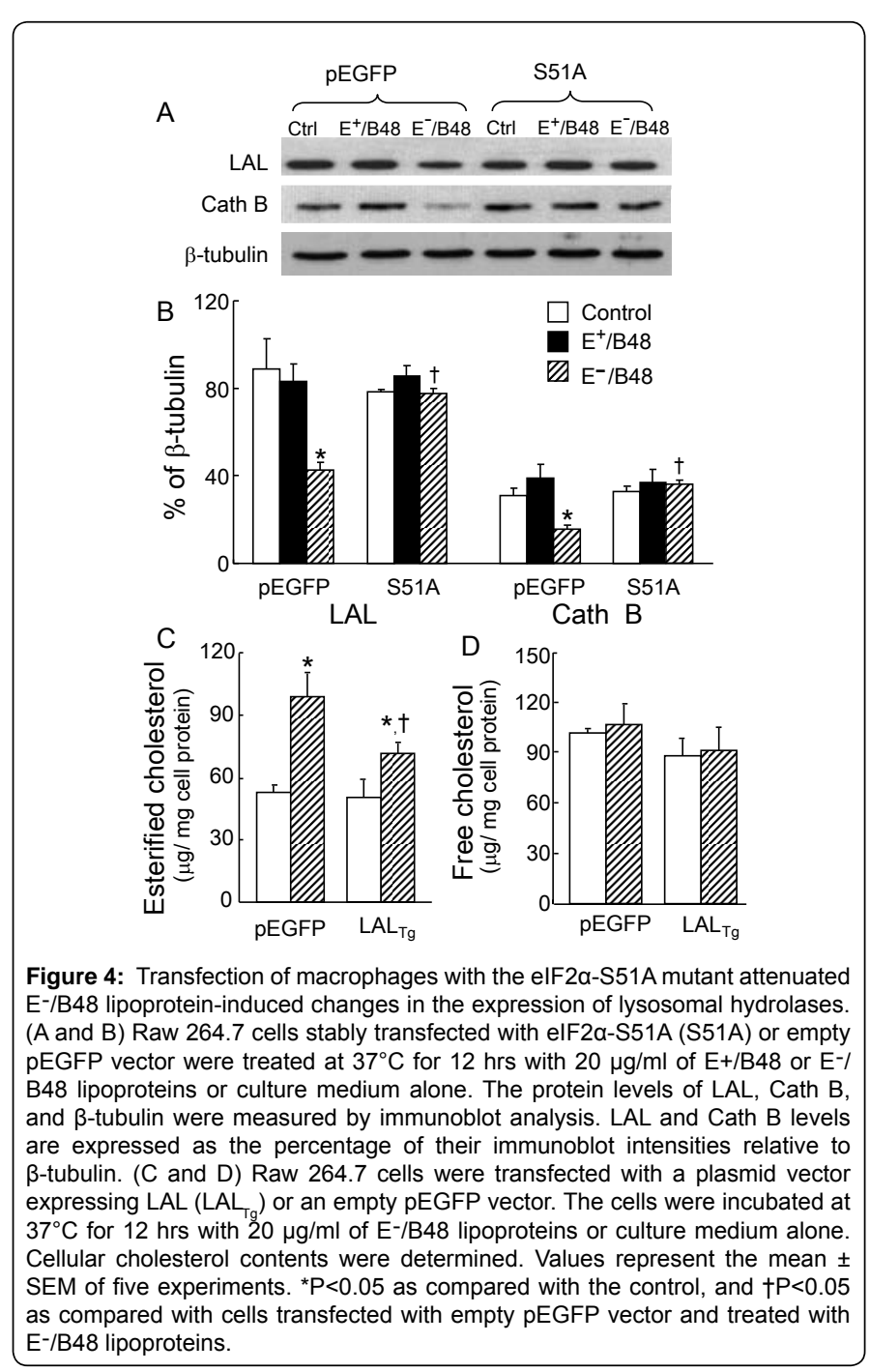




\section{Overexpression of the eIF2 $\alpha$-S51A mutant attenuated the suppressive effect of $\mathrm{E}$-/B48 lipoproteins on lysosomal hydrolase expression}

Lysosomal acid lipase (LAL) and cathepsin B (Cath B) are the acid hydrolases that hydrolyze lipoprotein cholesterol esters and proteins, respectively (O'Neil et al.,2003; Zschenker et al., 2006). As shown in Figure $4 A-B$, the protein levels of $L A L$ and Cath $B$ remained unchanged in cells treated with $\mathrm{E}^{+} / \mathrm{B} 48$ lipoproteins as compared to the control cells without lipoprotein treatment. There was no significant difference between cells transfected with the empty vector and the eIF2 $\alpha$-S51A mutant (Figure 4A-B). In contrast, the protein levels of LAL and Cath B were reduced approximately $50 \%$ in the empty vectortransfected macrophages after treated with E-/B48 lipoproteins. However, E-/B48 lipoprotein treatment did not significantly alter the LAL and Cath B protein levels in the cells transfected with the eIF $2 \alpha-S 51 \mathrm{~A}$ mutant. These data suggest a causal role of elF- $2 \alpha$ phosphorylation in E-/B48 lipoprotein-reduced expression of LAL and Cath B proteins.

To study the role of LAL reduction in E-/B48 lipoprotein-induced foam cell formation, we introduced a LAL overexpression plasmid into MPMs that increased the LAL protein level about 4.6-fold as compared to the control cells (data not shown). Overexpression of LAL diminished E-/B48 lipoprotein-induced cholesterol ester accumulation in macrophages (Figure 4C). These observations suggest that reduction of LAL protein levels is, at least partially, a mechanism underlying E-/B48 lipoprotein-induced foam cell formation. This finding is consistent with previous reports showing that LAL supplementation inhibits atherosclerosis in mouse models (Du and Grabowski, 2004).
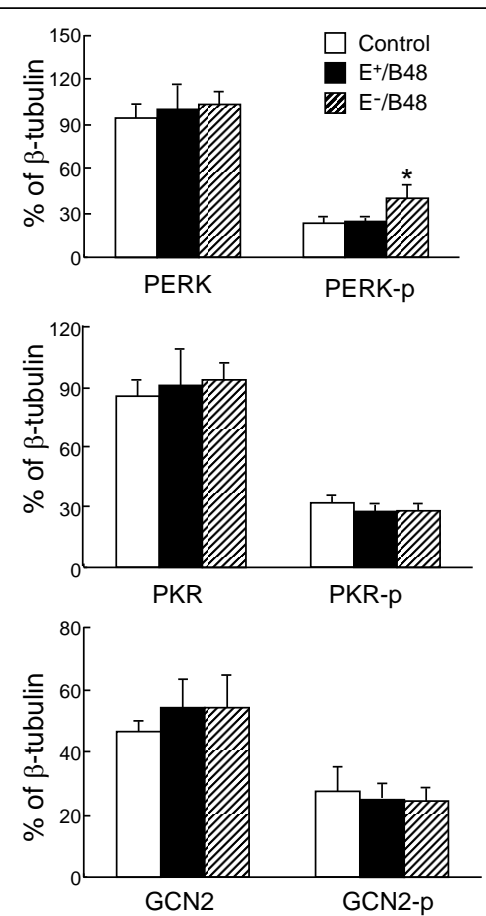

Figure 5: E-/B48 lipoproteins selectively activated PERK, but not PKR or GCN2. Raw 264.7 cells were incubated at $37^{\circ} \mathrm{C}$ for $12 \mathrm{hrs}$ with $20 \mu \mathrm{g} / \mathrm{ml}$ of E+/B48 or $\mathrm{E}-/ \mathrm{B} 48$ lipoproteins or culture medium alone (control). The total protein levels of PERK, PKR, and GCN2, and the phosphorylated forms of PERK (PERK-p), PKR (PKR-p), and GCN2 (GCN2-p) were determined by western blot analysis and expressed relative to $\beta$-tubulin protein levels. Values represent the mean \pm SEM of five separate experiments. ${ }^{*} \mathrm{P}<0.05$ as compared with the control.
To understand the mechanisms responsible for the E-/B48 lipoprotein-induced reduction of LAL and Cath B protein levels, we examined the steady-state level and the translation efficiency of mRNAs encoding these lysosomal hydrolases. $E^{+} / B 48$ lipoprotein treatment increased the steady-state level of LAL and Cath B mRNAs, but did not alter translation efficiency in the empty vector-transfected cells (Table 1). In contrast, incubation of these cells with E-/B48 lipoproteins significantly reduced the translation efficiency of LAL and Cath B mRNAs, but did not alter the steady-state levels of these mRNAs. $\mathrm{E}^{+} / \mathrm{B} 48$ and $\mathrm{E}^{-} / \mathrm{B} 48$ lipoproteins did not alter the steady-state levels or translational efficiencies of LAL and Cath B mRNAs in cells transfected with the eIF2 $\alpha$-S51A mutant. However, after treatment with $E^{-} / \mathrm{B} 48$ lipoproteins, the translational efficiencies of LAL and Cath B mRNAs in cells transfected with the eIF2 $\alpha$-S51A mutant was significantly higher than in cells transfected with the empty vector (Table 1). These data suggest that enhancing elF- $2 \alpha$ phosphorylation is an underlying mechanism by which $\mathrm{E}$-/B48 lipoproteins reduce the translational efficiency and protein levels of LAL and Cath B.

\section{E-/B48 lipoproteins selectively induced phosphorylation of PERK, but not other elF- $2 \alpha$ kinases}

There are four eIF- $2 \alpha$ kinases in mammalian cells, including HRI, PKR, GCN2, and PERK (Lewerenz and Maher, 2009; Wek et al., 2006). To identify the kinase(s) responsible for eIF- $2 \alpha$ phosphorylation induced by E-/B48 lipoproteins, we studied the effect of lipoproteins on PERK, PKR, and GCN2. HRI was not examined due to the lack of a specific antibody against-phosphorylated HRI. As shown in Figure $5, \mathrm{E}^{+} / \mathrm{B} 48$ lipoproteins did not alter the total protein levels or the phosphorylated levels of PERK, PKR, and GCN2. However, the effects of E-/B48 lipoproteins on these kinases varied. Specifically, incubation of macrophages with $20 \mu \mathrm{g} / \mathrm{ml}$ of E-/B48 lipoproteins for $12 \mathrm{hrs}$ increased the level of phosphorylated PERK by $42.3 \%$ as compared to the cells treated with $\mathrm{E}^{+} / \mathrm{B} 48$ lipoproteins. The same $\mathrm{E}^{-} / \mathrm{B} 48$ lipoprotein treatment did not significantly enhance phosphorylation of PKR or GCN2. E-/B48 lipoproteins also did not significantly alter the total protein levels of any of these eIF-2 $\alpha$ kinases (Figure 5).

\section{Overexpression of the PERK-K618A mutant inhibited elF-2 $\alpha$ phosphorylation and cholesterol ester accumulation induced by E-/B48 lipoproteins}

We demonstrated the selective activation of E-/B48 lipoproteins on PERK. Therefore, we next examined the causal role of PERK phosphorylation on eIF- $2 \alpha$ phosphorylation by overexpression of a PERK-K618A mutant. E-/B48 lipoproteins elevated the phosphorylation levels of endogenous PERK and eIF- $2 \alpha$ in MPMs transfected with the empty plasmid vector, but not in the PERK-K618A-transfected cells (Figure 6A-D). In contrast, $\mathrm{E}^{+} / \mathrm{B} 48$ lipoproteins did not significantly alter the phosphorylation and protein levels of PERK and eIF- $2 \alpha$ in MPMs transfected with either the empty plasmid vector or the PERKK618A mutant. These observations provide direct evidence that PERK is a kinase responsible for elF- $2 \alpha$ phosphorylation in macrophages treated with $\mathrm{E}-\mathrm{B} 48$ lipoproteins.

Data in Figure 6E and 6F show the effect of overexpressing the PERKK618A mutant on cellular cholesterol content. The MPMs transfected with the empty plasmid vector or the PERK-K618A mutant exhibited comparable levels of esterified and free cholesterol in the absence of lipoprotein treatment. Incubation of the cells with $\mathrm{E}^{+} / \mathrm{B} 48$ lipoproteins did not significantly alter the cholesterol content. However, E-/B48 lipoprotein treatment increased the esterified cholesterol in both the empty plasmid vector- and the PERK-K618A mutant-transfected cells. The magnitude of the increase was significantly lower in the latter. 

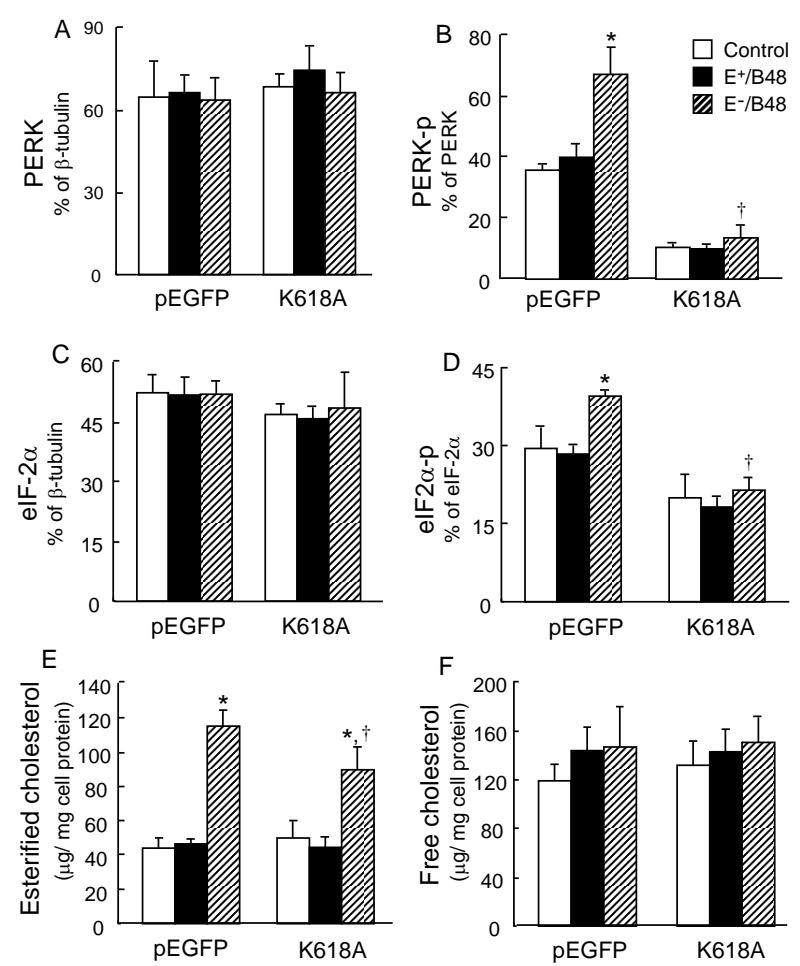

Figure 6: Transfection of macrophages with the PERK-K618A mutant attenuated E-/B48 lipoprotein-induced PERK and elF-2 $\alpha$ phosphorylation and cholesterol ester accumulation. Raw 264.7 cells were transfected with a plasmid vector expressing PERK-K618A (K618A) or an empty pEGFP vector. Cells were incubated at $37^{\circ} \mathrm{C}$ for $12 \mathrm{hrs}$ with $20 \mu \mathrm{g} / \mathrm{ml}$ of $\mathrm{E}+/ \mathrm{B} 48$ or $\mathrm{E}^{-} / \mathrm{B} 48$ lipoproteins or culture medium alone (control). (A-D) Total protein levels of PERK and elF$2 \alpha$ and the phosphorylated forms of PERK (PERK-p) and elF-2 $\alpha$ (elF2 $\alpha-p)$ were determined by western blot analysis and expressed relative to $\beta$-tubulin protein levels. ( $E$ and $F$ ) Cellular cholesterol contents were determined. Values represent the mean \pm SEM of five separate experiments. ${ }^{*} P<0.05$ as compared with the control, and $\dagger \mathrm{P}<0.05$ as compared with cells transfected with empty pEGFP vector and treated with E-/B48 lipoproteins.

E-/B48 lipoproteins did not significantly alter the free cholesterol content in MPMs transfected with either the empty vector or the PERK-K618A mutant. These observations, together with the data in Figure 3, suggest that activation of the PERK-eIF2 $\alpha$ signaling pathway is a mechanism by which E-/B48 lipoproteins induce macrophage cholesterol ester accumulation.

\section{Discussion}

Our previous studies showed that foam cell formation induced by E-/B48 lipoproteins was associated with increased elF-2 $\alpha$ phosphorylation (Wu et al., 2008). Data from the present study demonstrate that E-/B48 lipoproteins selectively activated PERK, but not other eIF- $2 \alpha$ kinases, including PKR and GCN2. In addition, inhibition of PERK phosphorylation by overexpression of a PERKK618A mutant suppressed induction of eIF- $2 \alpha$ phosphorylation and cholesterol ester accumulation by E-/B48 lipoproteins. These observations suggest that induction of PERK phosphorylation in response to treatment of macrophages with $\mathrm{E}-/ \mathrm{B} 48$ lipoproteins is an underlying mechanism behind eIF- $2 \alpha$ phosphorylation and the subsequent cellular events. A schematic diagram of these events is presented in Figure 7.

A characteristic of E-/B48 lipoprotein-induced foam cells is the accumulation of lipoproteins in endosomes/lysosomes, which is associated with a decreased degradation rate of E-/B48 lipoproteins and reduced LAL and Cath B protein levels (Wu et al., 2007). Cath B is one of the lysosomal proteases that degrade protein components of the internalized lipoproteins, while LAL is the sole enzyme to hydrolyze cholesterol esters in endosomes/lysosomes. Data from the present study showed that overexpression of LAL alleviated cholesterol ester accumulation induced by E-/B48 lipoproteins. These findings suggest that reduction in lysosomal hydrolases, such as LAL, is a mechanism responsible for the reduced degradation rate of $\mathrm{E}^{-/ B}$ 48 lipoproteins in macrophages. It is highly likely that $\mathrm{E}^{-/ B}$ 48 lipoproteins down-regulate lysosomal hydrolases, such as LAL and Cath B, which in turn reduces the degradation of E-/B48 lipoproteins, resulting in intralysosomal $\mathrm{E}^{-} / \mathrm{B} 48$ lipoprotein accumulation and induction of foam cell formation.

Data from the present study and our previous report demonstrate that E-/B48 lipoprotein treatment did not alter the steady-state levels of LAL and Cath B mRNAs, but did significantly reduce the translation efficiency of these mRNAs. This suggests that decreased translation efficiency is at least partially, responsible for the reduced protein levels of these lysosomal hydrolases in MPMs treated with E-/B48 lipoproteins.

It has been well established that reduction in translation of all the mRNAs, except for ATF4, is a hallmark consequence of eIF- $2 \alpha$ phosphorylation (Roybal et al., 2005). Indeed, E-/B48 lipoproteininduced eIF- $2 \alpha$ phosphorylation was associated with reduced global translation (Wu et al., 2008). Our data also demonstrated that inhibition of elF- $2 \alpha$ phosphorylation by overexpression of the elF $2 \alpha$ S51A mutant diminished the suppressive effect of E-/B48 lipoproteins on global translation, restored LAL and Cath B expression levels, increased E-/B48 lipoprotein degradation, and attenuated $\mathrm{E}^{-} /$ B48 lipoprotein-induced intracellular lipoprotein and cholesterol ester accumulation. These findings suggest that induction of eIF$2 \alpha$ phosphorylation is a mechanism by which $\mathrm{E}^{-} / \mathrm{B} 48$ lipoproteins down-regulate lysosomal hydrolases, such as LAL and Cath B, which in turn reduces the degradation of E-/B48 lipoproteins resulting in intralysosomal E-/B48 lipoprotein accumulation and induction of foam cell formation (Wu et al., 2008).

Taken together with the established knowledge of the UPR signaling pathways, our studies suggest the following model for formation of macrophage foam cells induced by E-/B48 lipoproteins

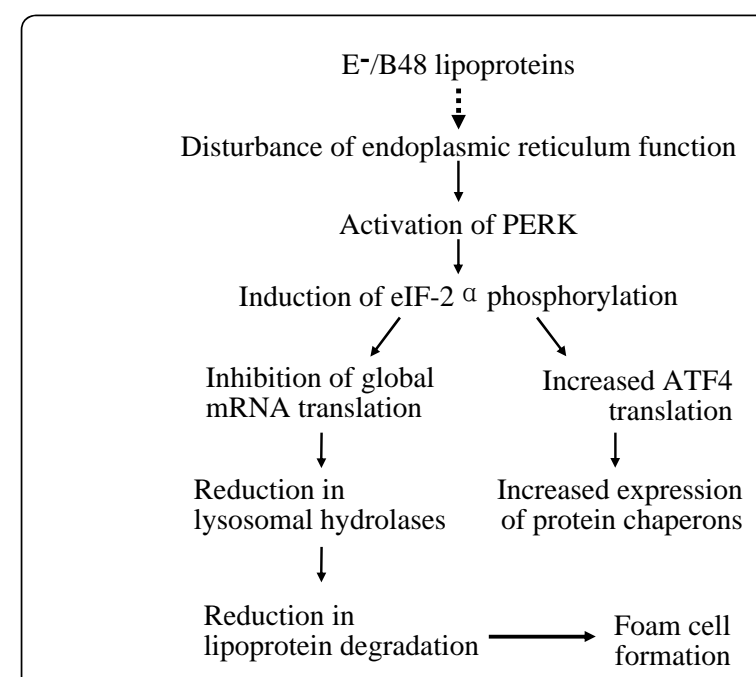

Figure 7: A model for the formation of macrophage foam cells induced by E-/B48 lipoproteins. 
Citation: Zhao Y, Guo Z, Lin X, Zhou L, Okoro EU, et al. (2010) Apolipoprotein E-Deficient Lipoproteins Induce Foam Cell Formation by Activation of PERK-EIF-2a Signaling Cascade. J Bioanal Biomed 2: 113-120. doi:10.4172/1948-593X.1000033

(Figure 7). E-/B48 lipoprotein loading disrupts ER homeostasis in macrophages through undefined mechanisms, and results in detachment of PERK from the luminal chaperone protein Bip, an event that is typically induced by unfolded and/or misfolded ER proteins. Freed PERK proteins associate with each other and become activated by autophosphorylation. Activated PERK in turn phosphorylates eIF- $2 \alpha$ at serine 51 . Phosphorylated eIF- $2 \alpha$ inhibits global mRNA translation and global protein synthesis, reducing the protein levels of lysosomal hydrolases, such as LAL and Cath $\mathrm{B}$. A reduction in lysosomal hydrolases decreases E-/B48 lipoprotein degradation, leading to lipoprotein and cholesterol ester accumulation in the endosomes/lysosomes, transforming macrophages into foam cells. The data from this study suggest that therapeutic intervention to inhibit the PERK-eIF2 $\alpha$ signaling pathway may be an effective strategy to reduce atherosclerosis.

\section{Acknowledgements}

This study was supported by NIH grants SC1HL101431 (Hong Yang) and R01HL089382 (ZhongMao Guo).

\section{Conflict of Interests}

The authors have no conflicts to disclose.

\section{References}

1. Daskal I, Ramirez SA, Ballal RN, Spohn WH, Wu B, et al. (1976) Detergent lysis for isolation of intact polysomes of Nivikoff hepatoma ascites cells. Cancer Res 36: 1026-1034.

2. Donzé O, Jagus R, Koromilas AE, Hershey JW, Sonenberg N (1995) Abrogation of translation initiation factor elF-2 phosphorylation causes malignant transformation of NIH 3T3 cells. EMBO J 14: 3828-3834.

3. Du H, Grabowski GA (2004) Lysosomal acid lipase and atherosclerosis. Curr Opin Lipidol 15: 539-544.

4. Glass CK, Witztum JL (2001) Atherosclerosis. the road ahead. Cell 104: 503 516.

5. Harding HP, Zhang Y, Ron D (1999) Protein translation and folding are coupled by an endoplasmic-reticulum-resident kinase. Nature 397: 271-274.
6. Koritzinsky M, Magagnin MG, van den Beucken T, Seigneuric R, Savelkouls K et al. (2006) Gene expression during acute and prolonged hypoxia is regulated by distinct mechanisms of translational control. EMBO J 25: 1114-1125.

7. Lewerenz J, Maher P (2009) Basal levels of elF2alpha phosphorylation determine cellular antioxidant status by regulating ATF4 and $\mathrm{xCT}$ expression. J Biol Chem 284: 1106-1115.

8. O'Neil J, Hoppe G, Hoff HF (2003) Phospholipids in oxidized low density lipoproteins perturb the ability of macrophages to degrade internalized macromolecules and reduce intracellular cathepsin B activity. Atherosclerosis 169: $215-224$

9. Roybal CN, Hunsaker LA, Barbash O, Vander Jagt DL, Abcouwer SF (2005) The oxidative stressor arsenite activates vascular endothelial growth factor mRNA transcription by an ATF4-dependent mechanism. J Biol Chem 280: 20331-20339.

10. Schröder M, Kaufman RJ (2005) ER stress and the unfolded protein response. Mutat Res 569: 29-63.

11. Tiwari RL, Singh V, Barthwal MK (2008) Macrophages: an elusive yet emerging therapeutic target of atherosclerosis. Med Res Rev 28: 483-544.

12. van den Beucken T, Koritzinsky M, Wouters BG (2006) Translational control of gene expression during hypoxia. Cancer Biol Ther 5: 749-755.

13. Wek RC, Jiang HY, Anthony TG (2006) Coping with stress: elF2 kinases and translational control. Biochem Soc Trans 34: 7-11.

14. Wu D, Sharan C, Yang H, Goodwin JS, Zhou L, et al. (2007) Apolipoprotein E-deficient lipoproteins induce foam cell formation by downregulation of lysosomal hydrolases in macrophages. J Lipid Res 48: 2571-2578.

15. Wu D, Yang H, Xiang W, Zhou L, Shi M, et al. (2005) Heterozygous mutation of ataxia-telangiectasia mutated gene aggravates hypercholesterolemia in apoEdeficient mice. J Lipid Res 46: 1380-1387.

16. Wu D, Yang H, Zhao Y, Sharan C, Goodwin JS, et al. (2008) 2-Aminopurine inhibits lipid accumulation induced by apolipoprotein E-deficient lipoprotein in macrophages: potential role of eukaryotic initiation factor-2alpha phosphorylation in foam cell formation. J Pharmacol Exp Ther 326: 395-405.

17. Zhao L, Ackerman SL (2006) Endoplasmic reticulum stress in health and disease. Curr Opin Cell Biol 18: 444-452.

18. Zschenker O, Illies T, Ameis D (2006) Overexpression of lysosomal acid lipase and other proteins in atherosclerosis. J Biochem 140: 23-28. 